
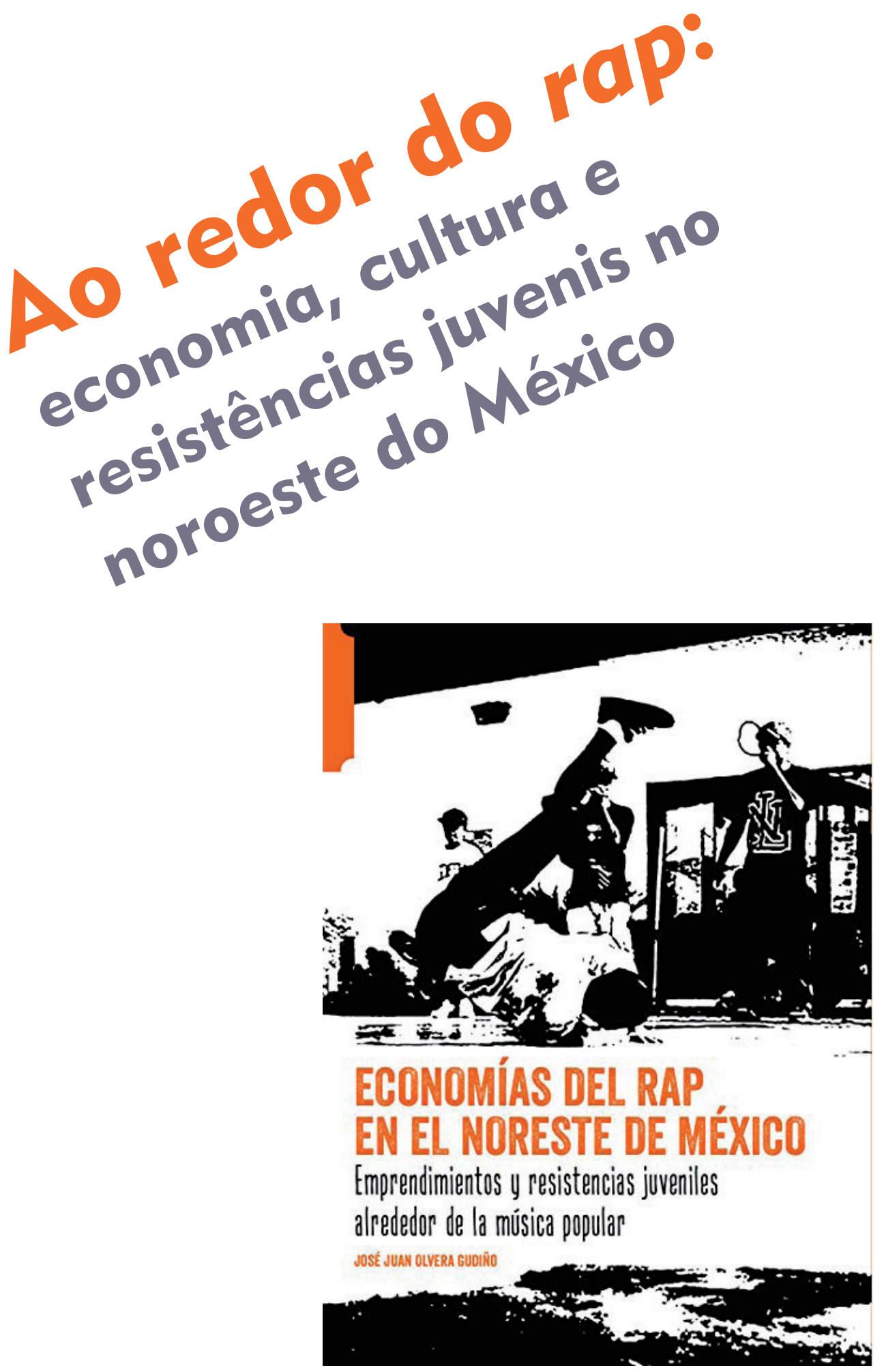

\title{
Roberto Camargos
}

Doutor em História pela Universidade Federal de Uberlândia (UFU). Pós-doutorando vinculado ao Programa de Pós-graduação em História da UFU. Bolsista PNPD/Capes. Autor de Rap e política: percepções da vida social brasileira. São Paulo: Boitempo, 2015. robertoxcamargos@gmail.com 


\title{
Ao redor do rap: economia, cultura e resistências juvenis no noroeste do México
}

Around rap: economy, culture, and youth resistances in northwestern Mexico

\author{
Roberto Camargos
}

OLVERA GUDIÑO, José Juan. Economías del rap en el noreste de México: empreendimentos y resistencias juveniles alrededor de la música popular. Ciudad de México: Ciesas, 2018, 274 p.

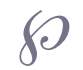

José Juan Olvera Gudiño, doutor em Humanidades e sociólogo das questões culturais, dedicou parte dos últimos sete anos de suas atividades profissionais - como professor e pesquisador do Centro de Investigaciones y Estudios Superiores em Antropología Social (Ciesas), localizado em Monterrey/México - a investigações acerca de músicas e artistas populares da região noroeste do México $^{1}$. Interessado especialmente nas experiências dos/das rappers, ele produziu e coletou uma vasta documentação sobre MCs, DJs, beatmakers, produtores culturais, empresários, lojistas, entusiastas e outros sujeitos que empenharam parte de suas vidas na configuração de uma cena local de hip hop. Conjugando elementos dessa rica pesquisa etnográfica e documental com pertinentes aportes teóricos, metodológicos e históricos, o autor analisa e descreve as redes econômicas e de sociabilidades em torno do rap sem perder de vista aspectos sociais de um contexto marcado por violências e inseguranças (física, social, econômica etc.). Dialogando com artistas e sujeitos de pouca projeção e com outros de inegável impacto em âmbito nacional, as análises expostas em Economías del rap en el noreste de México passam por processos econômicos, migratórios, educacionais, culturais, midiáticos e políticos, assinalando forte presença social do rap na região estudada.

O trabalho mobiliza reflexões sociais e material empírico variado na tentativa de entender aspectos relevantes das novas configurações culturais do país em que foi desenvolvido, elegendo como pilares do exercício de interpretação e análise social as dificuldades em se pensar os fenômenos culturais no México sem levar em conta os fluxos migratórios com os EUA, o papel dos jovens nos processos de culturalização da economia e, ainda, a importância de associar os dados e indicadores macrossociais às práticas dos jovens (como encaram a incerteza laboral e de renda, como criam meios de subsistência e como constroem redes de colaboração, por exemplo). Essas e outras potentes questões para se refletir sobre a sociedade e a cultura

${ }^{1} \mathrm{O}$ autor define o território delimitado para a pesquisa como um conjunto de espaços sociais formado pelos estados de Tamaulipas, Coahuila, Nuevo Léon e a parte sul do Texas, considerados ainda os vínculos socioculturais com Zacatecas, Durango e San Luis Potosí. emergem do interesse primário de José Juan Olvera: compreender e explicar o que fazem os rappers para viver com o rap e, especialmente, para viver do rap. Aqui, cabe destacar, viver com/do rap engloba um amplo e flexível conjunto de estratégias que permite a seus promotores a existência material (organização de eventos com vendas de ingressos, cobrança de cachês, venda de camisetas, produção musical, trabalhos educativos relacionados ou em diálogo com o hip hop) para criar e interpretar suas composições. 
O livro, que oferece ao leitor um substancial e detalhado painel das práticas vinculadas ao rap produzido por jovens de 15 a 35 anos da região noroeste do México, organiza sua narrativa em dois eixos expositivos que sintetizam os movimentos de pesquisa e reflexão enfrentados pelo autor. O primeiro, "Enfoques, conceptos y contexto sociohistórico", se debruça sobre a questões de ordem teórica e histórica. Já o segundo, "Etonografía. Economías del rap en el noreste de México", é focado na investigação empírica e documental que se valeu de fotografias, impressos diversos, dados estatísticos, indicadores sociais, diários de campo e de observação participante, entrevistas, músicas, vídeos e toda sorte de rastros que enriquecem suas análises. Ao final alinham-se conclusões gerais que resumem as condições de certos grupos de jovens mexicanos, submetidos a experiências de uma dinâmica laboral acelerada e de pouca estabilidade, expostos a vulnerabilidades sociais diversas e com vidas profundamente impactadas pela intensificação da violência no contexto/momento da pesquisa.

O capítulo 1, "La diversidad de economias en un contexto regional", é integralmente direcionado à construção de um contexto para a pesquisa. Aí o sociólogo descortina aos seus interlocutores o México do qual se ocupa, tomado como terreno de grandes e profundas diferenças regionais que atingem de maneira mais aguda enormes parcelas da juventude que constituem o grosso da população desempregada do país. Esses jovens tiveram suas vidas comprometidas pelas mudanças estruturais geradas pelas reformas neoliberais implantadas pelo Estado, que reduziu investimentos nas áreas sociais e abriu espaços da economia e da cultura para maior controle de empresas privadas, acelerando processos de acúmulo de desvantagens de setores mais pobres. O capítulo analisa, também, diferentes economias em torno da arte e que podem ajudar a caracterizar as práticas de músicos de rap dentro do recorte socioespacial da investigação, problematizando e adensando as reflexões sobre a partir das relações entre o local e o global.

Nas palavras de José Juan Olvera, “abordo primero el enfoque de las industrias culturales y creativas, así como sus limitaciones y alcances. A continuación, lo pongo em discussión con otras economias que permiten una mejor explicación de mi evidencia empírica y las relaciono con prácticas, espacios y redes de relaciones en forma de escenas musicales" (p. 33). Além disso, o autor enfoca, pelo viés da economia da cultura e do contexto regional, problemas referentes às discussões sobre juventude, música, relações fronteiriças - o que conduz ao entendimento da região com base em trocas simbólicas e em fluxos de pessoas, e não pelas delimitações geográficas oficiais de Estado - e aspectos sociodemográficos, protagonismo cultural e consumo, novas tecnologias e seu papel nas configurações e produções culturais, práticas de economia alternativa, solidária e de resistência. Esse percurso, alimentado com muitos dados e indicadores extraídos de copiosa bibliografia consultada, ganha especial relevo ao evidenciar o

contraste entre macroindicadores sociales y económicos positivos y las realidades etnográficas que muestran precariedade, exclusión y violencia. Em la frontera noreste, los indicadores de regazo social, que están todos por encima de la media nacional, se vem opacados por otros indicadores de la violencia. [...] Frente a la engañosa buena situación de algunos indicadores queda la alternativa de la observación presencial; mis recorridos por Nuevo Laredo, Reynosa y Matamoros me revelaron que la violencia está expresada en el abondono de la ciudad, la desolación de suas 
calles, particularmente de sus zonas centro. Aun con sus particularidades, las tres ciudades compartían el hecho de estar militarizadas ( $p$. 37).

O capítulo 2, "Contexto histórico del rap en el noreste, 1985-2015", visa proceder a uma leitura da prática do rap na região e, mais especificamente, em Monterrey, que "es centro de la narración por su papel como espacio fundamental para el nascimento y desarrollo de casi todas las variantes del rap, y por su influencia hacia a fuera de la región y más allá, como referencia del rap mexicano" (p. 61). É o momento em que José Juan Olvera detém-se em detalhes que conformam a chegada da prática de ouvir e cantar raps em Monterrey e, progressivamente, em toda a região noroeste pelos circuitos da indústria cultural e dos trânsitos de migrantes entre México e EUA. Se isso comporta semelhanças e possíveis pontes com o caso brasileiro e de outros países da América Latina, a circulação de informações e produtos culturais relativos a essa prática por meio de fluxos de migrantes (notadamente trabalhadores das camadas populares) the confere peculiaridades que impactam seus significados na realidade local e a geração de uma nova cultura juvenil do país. O autor, por intermédio de seu corpus documental, mostra que "el hip hop en general y el rap en particular llegaron a México casi desde sus próprios inicios, allí donde hubiera migrantes presentes en las escenas fundantes, que retomaran algo de su cultura y que, al retornar a México, la compartieran con sus pares mexicanos" (p. 63).

A longa trajetória dos praticantes do rap no México o leva a dividir o processo histórico de seu desenvolvimento em quatro fases: (a) as apropriações iniciais graças às famílias transnacionais que aceleravam a circulação de informações, dados culturais e objetos como discos, revistas, fitas e indumentária entre 1985-1989; (b) a consolidação de uma cena de música rap na região noroeste, marcada pela existência dos primeiros grupos locais, pela consolidação de espaços populares que acolhiam performance de variados elementos da cultura hip hop, pela produção dos primeiros discos e pela constituição de uma identidade - nomeada de rap chicano que "tiene un poderoso componente del gangsta rap, alusivo a la vida de pandillas, la vida del barrio, las drogas, la defensa del territorio y la vida criminal dentro y fuera de las prisiones" (p. 85) entre 1990 e 1999; (c) um momento de clímax expresso pelo número de grupos, pela diversidade dos agentes culturais e pela existência de espaços destinados exclusivamente ao rap/hip hop entre 2000 e 2005; e (d) uma fase de crise das práticas públicas ligadas ao rap e um intenso processo de declínio da cena na região, fruto de dinâmicas próprias da vida dos praticantes e do crescimento da violência em algumas zonas urbanas, entre 2006 e 2013, que "dejaro nun impacto específico importante: el narcorrap, un subgénero que canta a los comandantes y la gente alegada a las organizaciones criminales, ya sea para narrar su muerte en memoria, o para ensalzar sus cualidades en vida" ( $p$. 93). Esse itinerário elaborado pelo autor para o rap do noroeste do México, no entanto, não é um ponto de chegada, mas um ponto de partida: “El rap como industria sufre, pero como cultura resiste y se extiende. Dejó de verse y cantar seen bares, pero se refugió y a crecido en las casas, al igual que otras expresiones juveniles" (p. 95).

No capítulo 3, “Monterrey: una escena en recomposición”, o pesquisador segue os rastros de uma cultura que, eclipsada no espaço público pela violência das ruas, se instalou nas esferas do privado para se reconfigurar 
em novas formas e práticas: “el periodo de intensa violencia había terminado com gran parte de la vida nocturna: los jóvenes habían abandonado las esquinas y convertido las casas en centros de reunión, laboratorios de creación y hasta en pequenos negocios" (p. 104). O sociólogo lança mão de depoimentos (ao todo foram efetuadas 25 entrevistas) e outros documentos para tecer um significativo painel da recomposição da cena local de rap, caracterizado pela hegemonia do "rap consciente", assim chamado "porque no sólo hace un retrato de uma situación o narra una circunstancia, sino que toma una posición crítica respecto a las causas que originan tales hechos" (p. 101).

Delineia-se aí o profundo e rigoroso trabalho etnográfico da pesquisa, à medida que se relatam e se analisam em minúcias as novas figurações das práticas dos rappers e os espaços de produção do "novo" rap (beneficiado, em muito, pelo avanço das tecnologias computacionais e pela popularização da internet). Em meio a tudo isso, atenção especial é dispensada à economia - em sua maior parte dominada pela informalidade - que se formou em torno das atividades concernentes ao rap. De maneira original e criativa, Juan José Olvera elege os cartazes e flyers de eventos e shows para mapear o crescimento ou decréscimo no número de festas, preços de entradas, existência ou não de patrocinadores, artistas, espaços e relações econômicas no interior da cena de rap e o seu potencial como gerador de renda para as pessoas envolvidas com eles. Nos três capítulos subsequentes, o autor envereda por casos de jovens que trabalham conectados ao mundo do rap, ainda que de modos e de perspectivas diversificados.

Daí que, no capítulo 4, "Economías de la escena subterránea", o foco se concentra no exame pormenorizado de situações coladas ao ambiente underground de rap, principalmente os empreendimentos artísticos regionais que não estão presentes nos meios massivos de comunicação e nas redes da indústria cultural e do entretenimento musical. Assim, destacam-se as práticas e artistas de resistência, "que defino como formas de valorización de la producción musical del rap para la sobrevivencia económica, en medio de ambientes particularmente hostiles" (p. 114). Integram esse campo os "raperos de pesera", jovens artistas que utilizam o transporte público para cantar suas rimas e fazer algum dinheiro, os "narcoraperos", que produzem, mediante pagamento, composições encomendadas por pessoas associadas ao crime organizado ["llamadas 'dedicaciones', o réquiems, 'descanse en paz'”' (p. 152)] e que buscam legitimar e eternizar sua figura por meio de uma narrativa épica, e uma vasta rede de artistas, grupos, crews e "famílias" que movimentam atividades econômicas alternativas, solidárias e destoantes das operações e valores dominantes do capitalismo neoliberal. As reflexões são, pois, alinhavadas com base em trajetórias pessoais e artísticas, evidenciando que, para José Juan Olvera, a economia da música não está centrada em ver como a música sustenta o artista, mas, sim, em entender como se financia a atividade artística.

O capítulo 5, "Economías de la escena alternativa independiente", centra fogo em casos de rappers com maior nível de escolarização formal, como alguns pertencentes a estratos socioeconômicos médios. Calcado nas experiências de Erik Santos, Aldo Ce, DJ Jonta e do grupo Caballeros del Plan G, a análise privilegia projetos musicais que expressam ou são desenvolvidos sob lema "faça você mesmo" ou em práticas de economias alternativas em conexão com pequenos empreendimentos culturais. $\mathrm{O}$ autor salienta que nas práticas e discursos desses sujeitos há linhas de continuação

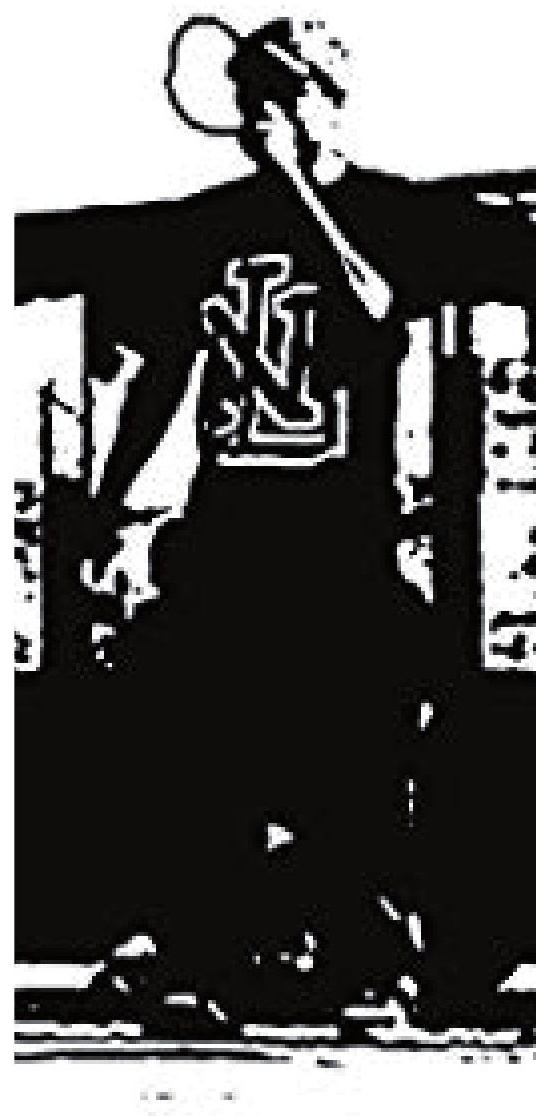


${ }^{2}$ Ver AZEVEDO, Amailton Magno. No ritmo do rap: música, cotidiano e sociabilidade negra - São Paulo, 1980-1997. Dissertação (Mestrado em História) - PUC-SP, São Paulo, 2000, e FELIX, João Batista de Jesus. Hip hop: cultura e política no contexto paulistano. Tese (Doutorado em Antropologia Social) - USP, São Paulo, 2005.

${ }^{3}$ Ver CAMARGOS, Roberto. Rap e política: percepções da vida social brasileira. São Paulo: Boitempo, 2015, e SILVA, Rogério de Souza. A periferia pede passagem: trajetória social e intelectual de Mano Brown. Tese (Doutorado em Sociologia) - Unicamp, Campinas, 2012.

${ }^{4}$ Ver SILVA, José Carlos Gomes da. Rap na cidade de São Paulo: música, etnicidade e experiência urbana. Uberlândia: Edufu, 2015, MAGALHÃES, Maria Cristina Prado Fleury. Hibridações locais e processos identitários: o rap em Goiânia e Aparecida de Goiânia. Dissertação (Mestrado em Música) - UFG, Goiânia, 2015, e ANASTÁCIO, Edmilson Souza. Periferia é sempre periferia? Um estudo sobre a construção de identidades periféricas positivadas a partir do rap em Uberlândia-MG (1999-2004). Dissertação (Mestrado em História) - UFU, Uberlândia, 2005. dos valores e ideias dominantes na cidade de Monterrey, embaladas por uma cultural laboral e empresarial que concebe o trabalho como sentido da vida e promove certo culto ao empreendedorismo que aponta o homem industrioso como o símbolo máximo da cultura do esforço e dos valores liberais do progresso e da mobilidade social: "Sostengo que algunos discursos de los raperos recogidos en este capítulo, como las expresiones de Erik Santos, las actitudes de Aldo Ce [...] son expresión de esta realidade, y que se han fusionado o han embonado con la ideología do DIY, y han sido incubados y potenciados cuanto más tempo tienem sus famílias asentadas en la ciudad, absorbiendo esta práxis y visión del mundo" (p. 218).

Por fim, no capítulo 6, "Economías alrededor de la gestión cultural: antes, al lado y delante del Estado", o pesquisador dirige seus esforços para entender e descrever as práticas de rappers que trabalham em parceria ou como empregados de instituições públicas ou privadas da área cultural. As reflexões se voltam para pessoas que realizam atividades de produção cultural em nível institucional como parte de um conjunto maior de ações relacionadas às suas vidas como rappers e/ou agentes do universo do hip hop que, mesmo não sendo rappers, incorporam o rap na implementação de políticas culturais e/ou trabalham com o gênero como ferramenta de transformação ou intervenção social. Ao longo do capítulo se analisam as potencialidades e os limites do uso do rap como fator de empoderamento dos jovens - "se oferecen [...] cursos de historia y filosofia del rap, construcción de rimas, ejecución de performance o elaboración de pistas, entre otros" (p. 222) - e, também, a natureza das ligações entre esses sujeitos e as instituições que os forçam a viver em constante negociação para suportar "los vaivenes, inconsistencias e incongruencias de la política partidista vinculada a la gestión de la cultura" (p. 224). Após explorar os campos de tensões e os conflitos que nascem ou reverberam nas relações estabelecidas entre agentes do hip hop e instituições (especialmente as estatais) que não desejam acolher práticas cujos valores e ideias podem perturbar o sistema, o sociólogo se atém ao caso do Festival Callegenera de Monterrey, tido como um exemplo bastante exitoso das possibilidades das políticas públicas em torno das culturas juvenis e como espaço aglutinador e catalisador da cena local/regional.

Publicada no ano passado no México, a obra de José Juan Olvera Gudiño é, ainda, desconhecida entre o público brasileiro. Suas contribuições, no entanto, são muito relevantes para as Ciências Humanas e Sociais no país, principalmente se considerarmos que nos últimos dez anos é notável e crescente o interesse dos pesquisadores das mais diferentes áreas, no Brasil, pelas práticas culturais do hip hop (ou seja, pelo rap, break e/ou graffiti). Apesar da área/tema de estudos contar com pouca ressonância editorial, as revistas acadêmicas e os programas de pós-graduação, com seus bancos de dissertações e teses, atestam a presença do hip hop, e particularmente do rap, nas pesquisas dos acadêmicos brasileiros. Por aqui, os trabalhos exploram, por exemplo, as redes de sociabilidades ${ }^{2}$, as dimensões políticas dessa prática cultural ${ }^{3}$, o seu papel na constituição de processos identitários ${ }^{4}$ e muitas outras questões, porém são praticamente inexistentes estudos sobre uma economia do rap no Brasil. Sob esse aspecto, o livro Economías del rap en el noreste de México pode inspirar e abrir caminhos até então não trilhados pelos pesquisadores brasileiros. 